\title{
PROBLEMS OF THE ESSENCE AND STRUCTURE OF ANALOGY AS A METHOD AND RESULT OF SCIENTIFIC AND EDUCATIONAL COGNITION
}

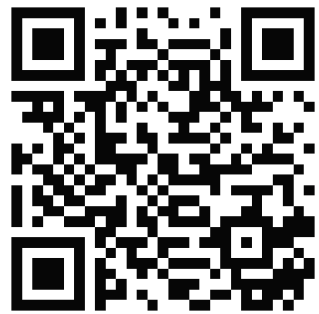

To cite this article:

\author{
Volodymyr Bondar, Dr. Sc., Prof. \\ Professor, Psychology and Pedagogy Chair, \\ National Pedagogical Dragomanov University, \\ Kyiv, Ukraine, \\ ipp_npu@ukr.net \\ https://orcid.org/0000-0002-5259-4870
}

\author{
Oleksandra Bozhok, PhD, Assoc. Prof. \\ Associate Professor, Methodology of Teaching Foreign Languages \\ Chair, \\ National Pedagogical Dragomanov University, \\ Kyiv, Ukraine, \\ o.s.bozhok@npu.edu.ua \\ https://orcid.org/0000-0002-0961-9008
}

Bondar, V. \& Bozhok, O. (2020). Problems of the essence and structure of analogy as a method and result of scientific and educational cognition. Education: Modern Discourses, 3, 6-12. https://doi.org/10.37472/2617-3107-2020-3-01

\begin{abstract}
From analogue as philosophical and logical and gnoseological essence up to its essence and structure as a method and result of the scientific and educational cognition that identifies the interactions of different systems, phenomena, objects. This is the conception idea and the intention of the author to open the leading gnoseological role and the place of analogy among other prognostic methods of experimental pedagogy and psychology. Analogy as the general scientific method under the certain conditions is able to interfere in the well-organized heuristic activity such methods as modelling, thoughtful experiment, retrospection, intuition and others. This is a topic of out discussion in the article.

Key words: analogy; analogue form of thinking; discourse; forms of inferences by analogy; judgment; inferences by analogy; model and prototype; types of analogue; scientific and educational cognition.
\end{abstract}

\section{INTRODUCTION}

In the theory of education and studying, many scientists consider differently the definition of the essence and classification of 'analogy' as the multi-limited, multi-sided and feature-rich phenomena. What is inside the definition 'analogue' as the category, term, and its division to types in the social, art humanities, natural sciences and in other sciences? We will try to find an answer to this question within our scientific and professional interest.

It is occurred, that the results of using the analogue as the method of our cognition are the most significant in physics. The significant role of the analogue in the cognition the 
famous scientist in nature Denis Diderot foud out: «In physics all our knowlegde are based on tht analogy; even if the similarity of results had given us the rights to make a conclusion about their equality, their reasons that what would it have happened? (Didro, 1939).

The wide using of analogy in physics as a science is an effective method of teaching phisics by a teacher on conditions of its bad organization. With the help of analogue on the phisical matherial there is an opportunity to condut an investigation by students or a teacher individually in the laboratory, and and to reveal connectors between the reason and result of the phenomena that are objects of their attention.

It is important to underline that with a development of the mathematics, physics and other natural sciences the analogue started loosing the key role in the definitions' demonstrability, the realization of the heuristic function of the studying at secondary and high school.

In the certain justification the role of the analogy in the development of sciences started decreasing because of its using as a term of synonymic comprehension with the term of comparison, relation, analogue. For the scientific cognition this definition of analogy does not have a value. The important part for it as for the method of scientific and educational cognition are thoughts conclusions. It provides the transferring from evident peculiarities, definitions, relations on the basis of similarities to the science cognition of new facts. The subject of necessary items for the researcher of new scientific knowledge is related to the educational field.

We will use the definition analogy as the external form of method of scientific and educational cognition. We will discover the process of thoughts conclusion as the form and result of the logical moving of thinking process of the subjects of new knowledge comprehension. They cannot be equal. They can be determined as the analogues or phenomena that can be compared with common or separate findings in structure, peculiarities, relations, functions etc.

Aim of the article is to define the place and role of analogy in the system of secondary and high school education.

\section{LITERATURE REVIEW}

The most outstanding scientists of natural sciences (Keler, Gallileo, Lomonosov, Maxwell, Einstein and others) demonstrated the high etalons of analogical findings by scientifically augmented analogy in their theories. The scholars explained their findings with the help of analogical comparisons in the scientific and illustration fields.

Thus, researchers used analogy as the heuristic factor that led us to guess thoughts, the others discovered this term as scientification of researched phenomena, hypothetical prognostics in the basis of which there were conclusions by the analogy. Moreover, the definition analogy is becoming the systematic, prognostic intention and the functional component of the modelling process. It is used as the mean of theoretical identification of a new discovery research or its rejecting.

Maxwell D. called such kinds of analogy the physical ones. To his mind they are something like similarity of relations and, although, laws. Because the law is an analogy of Maxwell D. between the electrical strong lines and tubes where the ideal liquid is transferring (Maxwell, 1954). Within the bright examples of this, he showed that "the recognition of the formal analogy among two systems of ideas leads to deeper cognition of them both than the cognition which was received while studying each system separately" (Maxwell, 1968: p. 8).

French mathematician gives the highest value of analogy, which was being used by mathematicians (Pifagor, Dekart, Eiler and others). DEO SOLAGES defined that: the theory of analogy covers almost all the Math Science" (Bondar, 1974). 
Analogy finds its development in the modern conditions of national language science, individual and common languages, their grammar structure, morphological processes without enthusiasm for national dialectical language. Nowadays one should behave carefully with analogies not to destroy the modern literary Ukrainian language. In addition, as less it ruins as quicker we will be approaching to the EU standards. Our language is beloved by the whole world but not by nationalists.

Ukraine needs not a former but a modern perspective influence of analogy on word formation. We do not think that the monograph of Feonila Nikitina ("The Influence of Analogy on Word formation" (on the material of a native language) Kyiv university publishing House 1973) is fully helpful for a goal achievement which the author aimed opposite her and her research users a half of a century ago.

Therefore, how did the analogy firstly, being a term and then as a scientific theory interfered into the humanities and to logics, language philosophy, psychology, pedagogy etc.? We will try to answer this question in general without underlining the stages of its formation and development under the influence of analogy.

\section{METHODOLOGY}

Examining a place and role of analogy in the cognition process, we can dialectically define that the course of thoughts conclusions was in two directions up to the beginning of $70-80^{\text {th }}$ of the 20 century. From the one side the role of the analogy was decreasing in the demonstrability of statements; and from the other side, the thought conclusions by the analogy were increasing on the highest level of generalization. They became scientific, methodological, conscious method of analogy with its approaches of comparison, observation, analysis, generalization, explanation and so on.

Traditional logics as a system of the scholars' ideas by the external and formal peculiarities is strongly developing. Although the inferences by analogy are reducing to the primitive approach of two phenomena similarity. Analogy by its structure and functions makes the researcher investigate the logical essence of analogue phenomena (inductive, deductive, traductive functions or their combination), and provide the researcher to make thought con inferences by analogy as the condition of its effective application.

\section{MAIN RESULTS}

Before the discovering the inferences by analogy, we define that its theoretical development closely connects with two conditions: striving for improving the method of analogy and increasing the adequacy of conclusions. These conditions are equal, though they are different by providing a specialist to do findings in the sphere of cybernetics, biology, physics, mathematics, humanities including pedagogy as well.

The intellectual scope of conclusions is provided by a discovery of conditions demonstrability of statements in the process of modelling the structure of research phenomena. Another words we mean the model of new object that is being discovered and model of its prototype as a mean of detailed cognition of new analogue. Inferences by analogy by their analogy are perceived as a result of transferring an information from the one phenomena to another model that is on the basis of structure similarity, functions, peculiarities, relations between them. Evaluating the role of analogue modelling the outstanding philosopher and methodologist V. Schtoff characterized the presence of traditional and modeling analogies (Shtoff, 1972). He demonstrated the difference between them. The traditional analogies mostly are limited by the comparison of individually defined characteristics. At the same time, in the 
modelling analogy not only isolated characteristics are compared but also the comparison of the completely systematic view of elements on the level of their relations and functions that is more comfortable for further researching. The thing is in the indissolubility of the connection between the definition of model in the science and technique and the definition in the theory and methodology as well as the educational practice.

Despite of this, it is not enough for feature-rich of modelling analogy in science and education but also for generalized, systematic defining of the analogy based on synergetics. It is very reasonable to add other items to a modelling analogy as the intuitive and theoretical parts. It may be considered well not only by professors but also by pupils while perceiving something new for their future.

The success of inferences by the modelling analogy in the scientific and educational fields mostly depends on the structure recognition and not only on the term recognition but also on the analogy as the peculiar logical form of thinking.

Hence the didactical multi-sided theory (external form), logical and psychological peculiarities, prognostic and research peculiarities (internal characteristics) the analogy as a method of cognition provides various means of actions, i.e. the movement from information from the knowledge resource to the individual cognition (the entry knowledge that becomes a cognitive compound of modelling analogy as a process or a method).

In this phase of the cognition and perceiving of new information (based on analogical prototype) the analogy as a method of interaction of external characteristics and its realization (word, visual, practical) influence on the perception of something new.

For the creation of logical base as a method of cognition by the sings of internal essence of scientific, theoretical and educational perception, we can define such kinds of actions as inductive, deductive, traductive, classified etc. With their help the scientist, professor (student), teacher (pupil) are guided by the thinking operations, develop critical thinking, seize such kinds of thinking operations as comparison, analysis, synthesis, abstraction, generalization, idealization etc.

Ukrainian didactics during $80-90^{\text {th }}$ years of $20^{\text {th }}$ - the beginning of the $21^{\text {st }}$ centuries by the common efforts led their investigations to the integral system of general methods of education where methods of education are defined as multi-sided, multi-limited and featurerich creation (A. Aleksjuk, S. Bondar, V. Bondar, V. Palamarchjuk and others).

Variety of the classification of cognition methods in didactics were just attempts to group methods of studying, which characterized their certain groups: external empirical form of cognition or internal essence by the characteristics of its functions; logics of knowledge development or the level of individual cognition in this process etc. Any of the classification did not perform completely all the complex of educational, cognitive, developing and educative functions of prognostic and researching education. This classification separated theoretical and methodological bases of application of new methods as analogy, idealization, modelling, thinking experiment, extrapolation methods, including critical thinking, intuition, insight and imagination into cognitive activity.

In the structure of inferences by analogy, we define elements that are compared. For example, object that contains the information that needs to be transferred to the model for recognizing a new analogue object with certain characteristics, relations and functions (i.e. prototype). Thus, the logical foundation of two objects is defined with their characteristics or relations. The conclusions of the totally or partly comparison of two models are also defined. That compiles the logical base of analogy with its characteristics, relations and functions and provides the inference by analogy.

Analogy being one of the forms of thinking reflects certain connection and relations to the objects of a real world in the human mind that exist independently from human intellect. 
Pretending on the autonomy, we have to underline that analogy as a method of new objective or subjective cognition of a human cannot become a productive one without researching and logical combination of methods in the structure of analogy as being a method and a process, a logical form of inference by analogy. With its help, the analogy can either confirm or refute the precious hypothetical supposition.

Thus, it is not occasionally that several outstanding researchers (Mil, Diderot, Stropovich, Gorsky) considered inferences by analogy as deductive ones (Spencer, Los'ky, Bakradze). To our mind, in the situations of modelling of such essences from findings of something new and different from a prototype of knowledge traductive method has the leading role (A. Aleksjuk, S. Bondar, V. Bondar).

We may suppose that these researchers just used a trick of F. Engels who tried to find a place of analogy addressing the to their unsuccessed attempts. He wrote: "These people stunk in opposition between induction and deduction that unite all forms of inferences by analogy. Moreover they: 1) unconsciously use different forms of inference by analogy under this term; 2) deprive themselves all the richness of forms of inferences by analogy, because they cannot be included into the frames of these forms; 3 ) in conclusion they reframe these forms (induction and deduction) into the nonsense". While understanding the real role of the analogy in the process of cognition by Engels F. "instead of raising a form into the clouds one should use each of them on their places” (Bondar, 1974).

We are convinced that analogy is important and individual from of inference by analogy as well as other ones. it would not be out of place to quote the words of Batoroyev K. about term 'analogy' "in the real process of the developing of scientific thinking the inferences by analogy make such kind of a 'bridge' between inductive and deductive methods of thinking" (Batorojev, 1974: p. 69-78). Mentioning the high productivity and the cognitive role of analogy of the science, we caution against insensible using analogy that can lead a researcher (scholar, student, teacher, and pupil) to make mistakes, to create a wrong inference by analogy, difficulties, and faulty arguments. This happens when researchers trust analogy and see it from general sides, forgetting about its wide characteristics and variety of functions. One should carefully use it while choosing, and never forget that there are forms of analogy that lead to reliable conclusions.

That is why the aim of established conclusions by analogy led us to adapt approaches to the modern conditions of pedagogical science and education and to the classification of conclusions by the analogy. Established conclusions by analogy led us to find out the dependency it on the chosen conclusion for conducting scientific and educational researching on the level of general didactical and methodological recommendations concerning the experience of previous researchers.

While doing an analysis of existing classifications of analogy we will try to take into consideration not only the character of information that transforms from the model to the prototype, but also the peculiarities of logical bases. This transformation is quite reasonable taking into account the proofs of concluded inferences by analogy.

As it is known, different authors consider not only the classification of analogy but also the classification of inferences by analogy. Some of them put on its foundation the proofs of conclusions and relatively to this; they divide analogy into strict and not strict, meaningful and nonsense, simple and controlling (by the character of the bases of conclusions - Gorsky D., Kondakov M.). Also, divide analogy by the signs of object that are compared, another words, the analogy of peculiarities of subjects and analogy of relations (Zherebkin V., Fres P., Piaget J.).

Types of analogy depend on many different factors. Thus, there can be factors that underline not only relations and peculiarities, structure of information and components that 
are transferred from one model to the prototype by the deductive method or vice versa by the deductive and inductive or deductive and traductive methods.

Individual researchers (Yuyomov A., Bondar S., Kostjuchenko R.) performed theoretical and methodological arguments of types of analogy. Yuyomov A., personally, having conducted a detailed analysis of analogy as a method of scientific cognition based on the natural and mathematical sciences, concluded:

* Firstly, theoretical knowledge can be grounded on the analogy as a form of human thinking;

* Secondly, inference by analogy can be approved for a science if the conclusion is grounded on the deductive inferences by analogy;

* Thirdly, inferences by analogy that are used on practice of scientific research can determine a leading role in finding a new knowledge in the educational practice.

It was mentioned above that the analogy of characteristics and relations between objects that are being compared found itself on the symbolical display on the scheme of relations of analogy and inferences by analogy (Fig. 1).

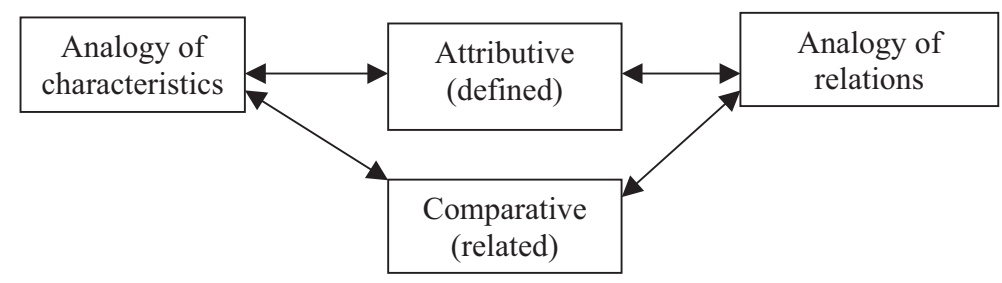

Fig. 1.

Types of inferences by analogy by two types of analogy (characteristics and relations)

Therefore, not only the character of information was taken into account but also a logical status and a base that provide the opportunity of this transformation.

Their character divides the types of analogy on three groups:

1) Real types where relations of compared subjects are defined;

2) Attributive (defined) types where in the base of inference of analogy there are the contrast of essential inalienable signs or characteristics of a subject that are compared;

3) Comparative inferences by analogy where its base or the base of general conclusion is present in comparison of cognitive and realized subjects.

As it is known, the analogy is included in the entire and syncretic process of thinking of any theoretical, creative, logical and visual types. It is an individual type of inference by analogy and it cannot be related neither to induction nor to the deduction, nor traduction that are independently on analogy considered as logical methods of moving of scientific and educational information.

\section{CONCLUSIONS}

To sum up, it is conceptual to conduct a further investigation of analogy as a mean of inference by analogy. We can define that analogy with inference by analogy are like a "bridge" between inductive and deductive modes of thinking. It is a modelled prototype. This idea will be transferred to discover the aspects of the role of analogy from the general methodological point of view (but natural and mathematical). We are going to find the place of analogy in education and pedagogical science in our further research. 


\section{REFERENCES}

Agapjev, F. (1904). Metod analogii v prepodavanii elementarnoj matematiki. [Method Of Analogy In The Teaching Of Elementary Mathematics]. Tiflis. (in Russian)

Batorojev, K. (1974). Kibernetika i metod analogii (pp. 69-78). [Cybernetics And The Method Of Analogy]. Moskva: Vyshaja Shkola. (in Russian)

Bondar, V. (2018). Analogia jak javysche v systemi prognostychnyh metodiv u pedagogizi [Analogy as the essence in the system of prognostic methods in pedagogy]. Naukoviy chasopys of Dragomanov Pedagogical University, 17, 8-16. (in Ukrainian)

Bondar, S. (1974). Dydactychni osnovy zastosuvannja analogii na urozi / nana materiali predmetiv pryrodnycho-matematychnogo zyklu [Didactical bases of applying analogy at the lesson / on the materials of natural and mathematical cycles] (PhD Tesis). Kyiv. (in Ukrainian)

DEO SOLAGES. (1946). Dialogue sur 1'Analogie. Paris

Didro, D. (1939). Sobranije sochineniy [The Collecton Of Essays]. In Encyclopedia (Vol. 7, p.192). Moskva: Hudozhestvennaja literatura. (in Russian)

Engels, F. (Ed.). (1953). Dialektyka pryrody [Dialectics of Nature]. Kyiv. (in Ukrainian)

Maxwell, D. K. (1954). O Faradejevyh silovych Linajah. [About Faraday Strong Lines]. Moskva: Gostehizdat. (in Russian)

Maxwell, D. K. (1968). O sootnoshenii mezhdu phisikoy s matematikoy. Statji i rechi [About the realtion between physics and mathematics. Articles and speeches]. Moskva: Nauka. (in Russian)

Mah, E. (2003). Poznanije I zabluzhdenije: ocherki po psihologii issledovanija [Cognition and Misconception: Psychological Research Essays]. Moskva: Binom. Laboratoria znanij. (in Russian)

Shtoff, V.A. (1972). Vvedenie $v$ metodologiju nauchnogo izdanija [Introduction to the methodology of scientific knowledge]. Leningrad: Publishing house of Leningrad State University. (in Russian)

Yuyomov, A.I. (1962). Analogia i model [Analogy and model]. Voprosy filosofii, 3. (in Russian) 